\title{
Contribution of Ecotourism Towards Sustainable Livelihood of the Communities Living on Wasini Island, Kwale County, Kenya
}

\author{
Jairus N. Koki \\ Eldoret National Polytechnic, Eldoret, Kenya
}

\begin{abstract}
Ecotourism has traditionally been viewed as a panacea concept for developing countries to stimulate the economy, as well as, directly provide support for conservation efforts. This study examined the concept of ecotourism for a relatively sustainable, single activity within an established tourism destination of Wasini Island in Kwale County. The purpose of the study was to assess the contribution of ecotourism initiatives to the livelihoods of the local community, guided by the following objective: to assess the attitude of the local community towards ecotourism development. Descriptive survey research was adopted for the study. The target population included all ecotourism entrepreneurs, conservationists, community based organizations (CBOs), and tour operators based in Wasini Island. Systematic random sampling was used to select 320 respondents. Primary data were collected using structured questionnaires while secondary data were obtained through critical examination of public and private recorded documents related to the study. Data were analyzed using techniques which included frequencies, means, modes and percentages. Ecotourism initiatives in the study area have significantly contributed to job creation and financial empowerment to the local people. Ecotourism in the study area has contributed to the acquisition of both human (education) and physical assets owned by the local community. Environmental conservation has also been achieved through ecotourism initiatives. In the face of joblessness, residents of Wasini need to be capacitated to venture into ecotourism projects as it has the potential of improving livelihoods.
\end{abstract}

Keywords: ecotourism initiatives, ecotourism development, sustainable livelihood, Wasini Island, attitudes, Kwale County

\section{Introduction}

Tourism is a phenomenon that is constantly evolving, developing, and reformulating itself as a consumer activity (Page, 2009). Tourism, as a consumer activity, is constantly being developed by the tourism industry and individual businesses, as marketing is used to develop new ideas, products and services and destinations (Page, 2009). Tourism is a complex phenomenon, one that is extremely difficult to describe succinctly (Goeldner \& Ritchie, 2012). Travel and tourism has many positive benefits, including that it is, for some countries, the main source of job creation and revenue (Tribe, 2006).

Tourism brings both economic and noneconomic benefits that include the contribution of pleasure travel to rest and relaxation, the educational benefit, the understanding of other people and cultures, and the physical and mental well-being of the traveller (Goeldner \& Ritchie, 2012). Tourism is a powerful, potential tool for

Jairus N. Koki, Ph.D. student, Business Department, Eldoret National Polytechnic. Email: kokijairus@gmail.com. 
economic development in lesser developed countries (LDCs). International tourism receipts reached US\$ 852 billion (611 billion Euros) in 2009 (Goeldner \& Ritchie, 2012). The fact that tourism is a principal export of $80 \%$ of developing countries and the first source of foreign exchange for all of the 49 LDCs aside from petroleum (Diaz, 2001) is highly significant - and merits a much deeper discussion within the international development community about the value of putting more expertise and investment into sustainable tourism as a means to alleviate poverty, improve human development indicators, drive economic growth, and conserve natural resources upon which the well-being of the poor depends.

Ecotourism is a form of tourism involving visiting fragile, pristine, and usually protected areas, intended as a low-impact and often small scale alternative to mass tourism (Randall, 1987). Its purpose may be to educate the traveller, to provide funds for ecological conservation, to directly benefit the economic development and political empowerment of local communities, or to foster respect for different cultures and for human rights. Within the academic literature, ecotourism has been advocated as an important community economic development strategy due to the potential direct economic and social benefits that the sector can generate to the local economy whilst protecting the natural resource base (Brandon, 1993; Christ, 1998; Goodwin, 1996; Ashley, 2000; Scheyvens, 2002).

Ecotourism activities using natural attractions in remote rural areas are promoted as an important source of economic diversification and livelihood opportunity (Ashley \& Roe, 1999; Ashley, 2000). The type and level of involvement of the local people helps to shape the benefits and costs they experience as a result of ecotourism activities in their lives.

Ecotourism is a sub-market of nature-based tourism that has received much attention in developing countries and economically impoverished regions around the world. It is an agent of change (Wall, 1997) and, as such, has been linked to resource protection policies, protected area conservation efforts, sustainable development initiatives and regional and community development strategies in many places (Ceballos-Lascurain, 1993; Wells, 1997). Ecotourism includes programs that minimize the negative aspects of conventional tourism on the environment and enhance the cultural integrity of local people and promotion of recycling, energy efficiency, water conservation, and creation of economic opportunities for local communities. For these reasons, ecotourism often appeals to advocates of environmental and social responsibility (Diaz, 2001). For example, in South East Asia, government and non-governmental organizations are working together with academics and industry operators to spread the economic benefits of tourism into the "kampongs" and villages of the region. A recently formed alliance, the South-East Asian Tourism Organization (SEATO), is bringing together these diverse players to allay resource management concerns.

In the developing countries of Sub-Saharan Africa, ecotourism is looked at in line with community development (Sindiga, 1999). It is considered as "responsible travel to natural areas which conserves the environment and improves the welfare of the local people". Ecotourism is hinged on the premise of promoting responsible travel to natural areas, make a positive contribution to environmental conservation, and enhance the well-being of local communities. As with any form of tourism, ecotourism can induce a variety of both positive and negative environmental, cultural, and socioeconomic impacts at a destination. While there is evidence that ecotourism's espoused benefits can be realized (Mitchell \& Reid, 2001; Slinger, 2000), there are equally as many cases where ecotourism has fallen short of its proposed objectives (Walpole \& Goodwin, 2000). 
In Kenya, ecotourism is regarded as nature and culture-based tourism that is ecologically sustainable and supports the well-being of local communities (Southgate, 2006). It appeals to visitors who want contact with nature, local communities, and indigenous cultures. Ecotourism targets travellers with special interests who are looking for unique and authentic experiences. It takes into account the impacts of the visitor industry upon the environmental, social, cultural, and economic fabrics of the local community and strives to conduct its activities in harmony with nature. Communities are therefore a key component of ecotourism (Fillion, Foley, \& Jacquemot, 2005).

Despite Wasini Island being a significant tourism destination, the poverty and underdevelopment are still evident at the Wasini community. Tourism should have a significant positive influence on the livelihood of the local community. Despite several ecotourism initiatives over time, no studies have been conducted to establish if these have improved or worsened the development status of the region or even remained the same. It is against this background that this study aims at exploring the contribution of ecotourism to community livelihoods on Wasini Island, Kwale County. Ecotourism has become increasingly popular with conservation and development organizations looking for means of generating income from the ecotourism sites. As ecotourism in an area grows, the local economy experiences some success as development starts to be seen. Once ecotourism has boosted an economy, locals gain and development starts to be seen in the community, giving them a better understanding of world issues like sustainable economic development for the host population of the Island. Thus, the research seeks to assess the contribution of ecotourism to the livelihood of the communities living on Wasini Island, Kwale County, Kenya.

Specific objective: To assess the attitude of the local community towards eco-tourism development at Wasini Island.

Research question: What is the attitude of the local community towards eco-tourism development on Wasini Island?

\section{Justification and Significance of the Study}

Ecotourism is viewed as an important element in regard to the improvement of the livelihood of the local community. The study was justified because it provides the avenue where ecotourism initiatives can be assessed on whether they contribute to the livelihood of the locals. The findings of this study can help scholars undertake studies in the area of ecotourism and sustainable livelihood. Study results can aid government officials in the area of planning for ecotourism development. The research findings can be instrumental to the policy makers and opinion leaders of the tourism sector in drafting policies that would benefit all the stakeholders in the tourism industry. It can enlighten both existing and potential investors on key areas of investment in the tourism sector particularly in ecotourism and sustainable livelihood. The study envisions that the findings can offer an insight on mechanisms through which mass deprivation may be reduced within small island communities. Particularly, the study proposes ways of improving income earning opportunities of the host community, social amenities and participation of the host community in the development projects.

\section{Literature Review}

\section{Community Livelihood}

Definition of community livelihood. A livelihood comprises the capabilities, assets (including both material and social resources), and activities required for a means of living. A livelihood is sustainable when it can cope with and recover from stress and shocks and maintain or enhance its capabilities and assets both now 
and in the future, while not undermining the natural resource base (Chambers \& Conway, 1991). In order to better understand how people develop and maintain livelihoods, the UK Department for International Development (DFID), building on the work of practitioners and academics, developed the Sustainable Livelihoods Framework (SLF) (International Recovery Platform, 2010). This framework is an analysis tool, useful for understanding the many factors that affect a person's livelihood and how those factors interact with each other. The SLF views livelihoods as systems and provides a way to understand the assets people draw upon; the strategies they develop to make a living; the context within which a livelihood is developed; and those factors that make a livelihood more or less vulnerable to shocks and stresses (International Recovery Platform, 2010).

Livelihood assets. Assets may be tangible, such as food stores and cash savings, as well as trees, land, livestock, tools, and other resources. Assets may also be intangible such as claims one can make for food, work, and assistance as well as access to materials, information, education, health services and employment opportunities. Another way of understanding the assets that people draw upon to make a living is to categorize them into the following six groups: human, social, natural, physical, financial, and political assets.

Livelihood strategies. How people access and use these assets, within the aforementioned social, economic, political and environmental contexts, form a livelihood strategy. The range and diversity of livelihood strategies are enormous. An individual may take on several activities to meet his/her needs. One or many individuals may engage in activities that contribute to a collective livelihood strategy. Within households, individuals often take on different responsibilities to enable the sustenance and growth of the family. In some cultures, this grouping may expand to a small community, in which individuals work together to meet the needs of the entire group.

Livelihood interdependence. One final important characteristic of livelihoods is their interdependence. Very few livelihoods exist in isolation. A given livelihood may rely on other livelihoods to access and exchange assets. Traders rely on farmers to produce goods, processors to prepare them, and consumers to buy them. Livelihoods also compete with each other for access to assets and markets. Thus, positive and negative impacts on any given livelihood will, in turn, impact others. This is a particularly important consideration when planning livelihood assistance (International Recovery Platform, 2010).

Entitlement. An entitlement is a guarantee of access to benefits based on established rights or by legislation (Hamilton, 2003). A "right" is itself an entitlement associated with a moral or social principle, such that an "entitlement" is a provision made in accordance with legal framework of a society. Typically, entitlements are laws based on concepts of principle ("rights") which are themselves based on concepts of social equality or enfranchisement. In a casual sense, the term "entitlement" refers to a notion or belief that one (or oneself) is deserving of some particular reward or benefit, if given without deeper legal or principled cause, the term is often given with pejorative connotation (for example, a "sense of entitlement").

\section{Ecotourism}

Definition of ecotourism. The Ecotourism Society defines ecotourism as "responsible travel to natural areas which conserves the environment and improves the welfare of local people" (Western, 1993, pp. 7-11). Numerous similar definitions that include a community development and/or conservation component can be found in the literature (Ziffer, 1989; Whelan, 1991; Cater, 1994). For this study, the quite specific World Conservation Union (IUCN) Commission on National Parks and Protected Areas' (CNPPA) definition of ecotourism has been adopted. The revision of ecotourism's original definition, by the same author, aptly 
reflects the evolution that the concept has undergone since the early 1980s. Ecotourism has matured, its impacts becoming more evident and in some instances have been indistinguishable from mass tourism making definitions more elaborate (Campbell, 1999). It is now generally thought to be more complex than "just tourism to natural areas" (Ross \& Wall, 1999), and is increasingly defined to include aspects of resource conservation and local development.

Ecotourism products. Ecotourism experiences can range from a foreigner spending thousands of dollars coming to Africa on a commercial tour to visit the great national parks and the wet equatorial rainforests to a local resident camping over the weekend at an adjacent national park. Ecotourists might engage in a wide range of activities, including trekking (hiking, bushwalking), climbing, camping, hunting, photography, sight-seeing, fishing, bird watching, whale viewing, and general exploration of remote natural areas. Of particular interest, visitor surveys (Eagles, Ballantine, \& Fennell, 1992) and anecdotal reports indicate that many ecotourists feel it is important for their visit to contribute to conservation and local development. Though this is not important for all ecotourists, it does present additional motivation for businesses and government agencies to support conservation and development efforts.

Lindberg (1991) provided a typology of nature/ecotourism types, though many other typologies are possible: Hard-core scientific researchers or members of tours specifically designed for education, environmental restoration, or similar purposes. Dedicated people who take trips specifically to see protected areas and who want to understand local natural and cultural history. Mainstream people who visit the Amazon, the Rwandan gorilla park, or other such destinations primarily to take an unusual trip.

A study of the Great Himalayan National Park, in Kullu District of Himachal Pradesh, was to study the role of ecotourism in community development. Great Himalayan National Park ranks as one of the best national parks in the world and reveals its beauty, diversity, and depth through time spent in exploration. The ecotourism products include: hiking, trekking, wildlife watching and several villages that had some economic dependence on the resources of land that was incorporated into the park. Weaver (1999) identified the following in his findings as the ecotourism products, the hill walking, wildlife watching, and bird watching. These were types of ecotourism products that could be developed to target the market niche for ecotourism in Scotland.

The benefits of ecotourism for local communities can be broadly categorized as economic, socio-cultural, and environmental. The most direct economic benefits are the improvements in employment and income. The National Ecotourism Plan recognizes that local communities living at ecotourism site have generally low incomes. Hence, ecotourism provides a viable economic option for such communities. Before ecotourism gained popularity, the extraction of natural resources for the purpose of economic development such as forest logging, mining and land clearing for agricultural was the only source of income for these communities. However, these activities will eventually lead to environmental damage and ecological imbalances. Ecotourism, on the other hand, encourages responsible travel to natural areas that safeguards the integrity of the ecosystem and produces economic benefits for the local communities that can encourage conservation. Thus, ecotourism is a more sustainable development strategy, protecting the ecosystem and at the same time serving as an income and also employment provider for the local community (Weaver, 1999).

According to a report released by United Nations Environmental Programme (UNEP, 2001), with regards to socio-cultural benefits, since ecotourists are travellers seeking unique and authentic travel experiences, there is an added incentive for local communities to retain their traditional heritage and lifestyles for long-term viability. These include the preservations of religious architecture and symbols, rituals and ceremonies, arts and 
crafts, and even music and dance. Finally, the most direct physical benefits will be the conservation of the environment. Conservation will help prevent inappropriate development and practice that will lead to degradation of habitats and landscapes, depletion of natural resources and contribute to waste and pollution.

According to Sindiga (1996), the more people visit a natural location, the greater the possibility for degradation of local ecosystems and a decrease in biodiversity. Ecotourism in Kenya led to land-use change when pastoral lands were divided up and converted to farming. This change led to decreases in wildlife populations, with wildebeest populations decreasing by $80 \%$ and the overall game population in and around the reserve declining by $60 \%$. Tourism to the area has also changed the way people interact with the wildlife, with vehicles often crowding and harassing the animals. There is also a tendency of ecotourism destinations to focus on "flagship" species, such as dolphins and whales and large carnivores, rather than the entire ecosystem.

As developing countries become more dependent on ecotourism for revenue, it is important to remember that it is not always a stable source of income. According to Tribe (2006), tourism can be affected by the global economy, the local political situation, and natural disasters. Following the US bombing in September 11, 2001 and the current political and economic crisis, tourist bookings have faced substantial decline. A significant decline in tourism income could have a significant impact on the economy of a developing country. Also problematic is economic leakage, which occurs when international or non-local businesses fill the gap community businesses are not able to provide. Economic leakage not only funnels profits away from the local community; local, rural residents are often forced to bear the cost of conservation (restricted access to water, pasture lands, increase in population and others), while the benefits often go to others outside this group. Even when ecotourism is run by local communities, rather than international tour operators, the financial benefits are often limited to the elite or those in high government positions. Kenya is one of the countries which began one of the first community-run ecotourism programs, including local community participation and revenue-sharing (Miller, 1997).

As a result of ecotourism, local communities sometimes face crowding from visitors, as well as other indigenous people who move closer to the area to take advantage of the economic benefits such tourism has to offer (Cohen, 2003). These communities can also face excessive development in the form of hotels, restaurants, and stores. Sometimes, poorly planned projects and infrastructure are put into place quickly to meet tourism needs. Additionally, cultural change resulting from increased contact with the outside world is of concern. False or inflated ecotourism claims could have the potential to undercut the entire industry. Businesses that proclaim themselves a part of "ecotourism" without making any efforts to change their practices open themselves up to claims of "green washing".

Effect of ecotourism on community development. Genuine ecotourism should strive to combine these elements; Ecotourism is a responsible business opportunity, resulting in environmental and community benefits. These aims can be achieved in a number of ways depending on the landscape, local culture, economy, and conservation needs in the locality (Fillion et al., 2005).

According to Alderman (2000), ecotourism does not simply consist of environmentally sound eco-lodges; it provides a means for rural people to benefit from the wildlife and environment of which they have traditionally been custodians. It also requires a change from foreign owned mass tourism facilities to community-based ecotourism developments. Cohen (2003) asserted that ecotourism is often perceived as an excellent tool for promoting sustainable development in developing countries. Many view ecotourism as a viable way to protect the natural environment and create social and economic benefits for local communities. 
However, according to Weaver (2001), interest in ecotourism, now widespread among tourism planners and marketers, is rationalized by a number of popular assumptions regarding the sector's potential economic, environmental, and socio-cultural benefits. While some ecotourism projects can support such claims, many ecotourism projects have failed to address some fundamental issues and do not generate the very benefits ecotourism is intended to provide. When poorly planned and implemented, ecotourism can quickly turn economic gains into social and environmental disasters.

The benefits accrued from ecotourism must be focused on improving livelihoods as well as conserving biodiversity (Christie \& Crompton, 2001). A process of monitoring and evaluation should be incorporated into the business plan to assess changes in environmental factors and conservation goals in relation to other emerging factors and conditions. Within the monitoring program, controls and baseline data on social and economic standards and environmental aspects should be integrated to allow comparisons to be drawn. Ecotourism has several distinct features. The community must be involved as partners in the ecotourism enterprise, as opposed to superimposing a tourism enterprise upon them. With the expansion of this sector of the tourism industry, and the recognition of its potential positive impact on community development, this community involvement has become an increasingly important aspect of successful ecotourism initiatives (Miller, 1997).

Communities or landowners must initially decide whether ecotourism is the best land use option. Ecotourism is only one of a number of ways to generate benefits from natural resource management and other options should be quantified and compared with anticipated returns from ecotourism. It must also be accepted from the start that ecotourism is a long-term and alternative land use, which may challenge their established perception. Only by making this commitment at the start, will the enterprises experience benefits (Goeldner, 2001).

According to Honey (1999), it is virtually impossible to ensure that any development satisfies the needs of all members of the community. A committee or community-based organization, which represents the aspirations of the majority of the members of the community, must be established to act on behalf of the community as a whole. There are potential problems with such a community-based organization, such as corruption, and systems must be established to manage these problems at the community level. According to Ikiara (2001), the community-based organization should act as the community representative to external partners as well as to reporting progress back to the larger community. Regardless of the fact that ecotourism is not being properly planned and implemented in many instances, it has continued to gain popularity over the past two decades and has developed into a worldwide phenomenon that shows no signs of slowing down.

Ecotourism is currently the fastest growing sector of the global tourism industry (Ceballos-Lascurain, 1996). Most estimates indicate that the demand for ecotourism is growing at an annual rate of $10 \%-30 \%$ (Honey, 1999). Now that ecotourism has reached such stature, it is especially important to scrutinize its effectiveness as a strategy for sustainable development, and search for ways to improve policies and practices. Clearly, ecotourism is not a universal remedy; but its potential to promote sustainable development deserves considerable attention. As ecotourism has grown and evolved over the past two decades, so has our understanding of it. While the concept remains incredibly complex and surrounded by uncertainty, there is a solid foundation of literature, which provides a great deal of insight and perspective on the multitude of issues and questions surrounding the concept (Nash, 2001). 
It makes sense to use the fact that "ecotourism" sells for marketing purposes, but only when the product labelling conforms with both consumer expectations and industry standards (Wight, 1993). If ecotourism is used solely for image purposes, rather than an approach adopted in practice, the very landscape, culture and heritage that provides the initial attractions will disappear.

Concepts of ecotourism. According to Sindiga (1996), beaches, coastlines and islands are the most popular tourism products, accounting for about $60 \%$ of all bed-nights in Kenya. Environmental problems associated with tourism activity on coastlines include the development and urbanization of the coastline have threatened some species with extinction, such as the monk seal, sea turtles, crabs and many plant species. Concerning water pollution involving tests in 1997, for example, it is found that only 125 out of UK's 755 beaches met the Marine Conservation Society's standards for clean water (UNEP, 2001). In 1990, all of Thailand's hotels in Pattaya lacked sewage facilities and discharged raw sewage into the sea; only $60 \%$ of the hotels had acquired the facilities by 1996. Sewage runoff damages coral reefs by stimulating growth of algae, therefore interfering with the filter-feeding mechanisms of the corals (UNEP, 2001).

Beach erosion arising from coastal development such as buildings is known to alter patterns of sand movement (Nash, 2001). Studies have found up to $70 \%$ of the world's beaches to be eroded. Building of resorts often damages coral reefs, which are important tourist attractions. Boat anchoring, divers, and snorkelers all can damage corals. It is estimated that coral reefs in 90 of the 109 countries that have them are being damaged by these uses, plus sewage and other pollutants and by harvesting of coral either by tourists or for sale to tourists. Dive sites have carrying capacities estimated by some studies to be 4,000-15,000 dives per year. Violation of these limits leads to reef degradation. In addition, reefs are over-fished to meet tourist demands. Global warming partly caused by tourism leads to the rising in sea temperature, which is one of the greatest threats to coral reefs.

Wildlife tourism accounts for $10 \%$ of international tourism (Nash, 2001). The main impact of tourism on wildlife is disruption of their normal behavior, which affects their feeding and breeding patterns. In 1993, for example, two tourists counted 4,500 pieces of litter along a 10 kilometer stretch of trail on Mt. Kilimanjaro (Miller, 1997). They had lost their natural ability to digest vegetation. In third world national parks, cheetahs and lions have been found to hunt less when surrounded by more than six vehicles (Western, 1993). On Mexico's Pacific Coast, bright lights from beachfront hotels disorient female sea turtles heading ashore to lay eggs, often preventing successful reproduction (Nash, 2001).

Tourism can be a profligate consumer of natural resources, as demonstrated by the following examples: a large hotel in Egypt uses the quantity of electricity that could be used by 3,600 families, the amount of water used by a tourist in 3-6 days is enough to produce rice to feed for a year a whole village in developing countries, a hotel guest in the Philippines uses as much water in 18 days as would a rural family in a year, and a tourist in Spain uses 880 litres of water compared with 250 litres used by a local person. Golf courses use a lot of water and contribute to pollution from runoff. In the Philippines, for instance, the average golf course has been found to use 24 million gallons of water per month, which would be enough to irrigate 65 hectares of farmland or supply a 2,000-room, four-star hotel. In Spain, a golf course in Benidorm uses as much water as would 10,000 people. In Thailand, a typical golf course has been found to use 1,500 kilograms of chemical fertilizers, pesticides and herbicides a year and as much water as would be used by 60,000 villagers. Chemical runoff from pesticides and fertilizers pollutes rivers and kills wildlife (Weaver, 1999). 
Huge potential exists for hotels and resorts to reduce energy and water use through appropriate technology such as recycling, reduction of toilet flush volumes and use of energy-efficient light bulbs. A hotel in Canada, for example, reduced its waste by $85 \%$ by recycling wastewater from washing for use in flushing toilets and in irrigating lawns (Collins, 1998). Even without hard empirical data on environmental consequences of tourism in the country, evidence presented in this section shows that tourism is far from being environmentally benign. The activity is imposing substantial costs on its very base, the natural resources and the environment therefore seriously threatening its own sustainability.

Substantial attention is now directed at the impact of tourism on the environment, particularly in the National Tourism Master Plan, with forms of tourism that contribute to conservation of the environment being favored. The new policy focuses on conservation and utilization of tourism resources in a sustainable manner, conservation of the environment, preservation of scenic beauty, provision of visitor education on available resources and their interdependence, establishment of active partnerships with all stakeholders in tourism and respect of their rights, equitable distribution of tourism benefits, respect and safeguarding of the local customs and culture, and harmonious development of the tourism sector in tandem with other economic sectors (Christie \& Crompton, 2001). UN's first meeting on sustainable tourism in April 1999, attended by the tourism industry, national and local governments, trade unions and activist groups proposed that airlines show in-flight videos to educate tourists about environmental and cultural sensitivities of their destinations, governments develop national World Travel and Tourism Council (WTTC) successfully opposed a UN proposal to tax air travel to fund environmental protection, preferring instead to focus on the industry's self-improvement incentives and light-handed regulation as its millennium vision for the environmental policy agenda in tourism (Ottichilo, 2000).

\section{Methodology}

\section{Location and Bio-Physical Characteristics}

Wasini Island lies off the southern Indian Ocean coast of Kenya next to Shimoni, $75 \mathrm{~km}$ south of Mombasa. Wasini islands latitude is $4^{\circ} 42^{\prime} 45^{\prime \prime} \mathrm{S}$ and Longitude: $39^{\circ} 24^{\prime} 53^{\prime \prime} \mathrm{E}$. The island is found on the Kenyan Coast in equatorial latitudes, there are almost equal nights and days all year round. It is approximately $5 \mathrm{~km}$ long and $1 \mathrm{~km}$ across. The island is sparsely populated and undeveloped. There are no cars or roads. A site of early Swahili civilization, this coral island is occupied by the Vumba people, an indigenous group of Bantu-speaking people who have a rich history. They speak Swahili and Kivumba and they number about 1,500. Mkwiro and Wasini are the two villages present on the island - each at opposite ends. Their history includes invasion and settlement of Arab influence from the Persian Gulf states, and from the island of Zanzibar, further south. Located in south west Kenya, this population has the highest infant mortality rate in the country. Poverty levels are indicative of poor historical and current development.

Paradoxically, the island is some $10 \mathrm{~km}$ from the Kisite-Mpunguti Marine National Park. This park annually attracts many thousands of overseas and local tourists per year and is managed by the Kenya Wildlife Service. The tourist numbers generated in the area over the years are not monitored for environmental or socio-economic impact. Women groups on the island have established a nature walk in the beautiful coral gardens on the Western end. 


\section{Tourist Activities and Facilities}

In this tranquil setting, one will find interesting villages, ancient mosques, tombs, amazing coral formations, mangroves and happy inhabitants. Furthermore, the island that has steeped in history has a serene skyline which consists of ancient baobabs. The tourist activities include swimming pool, dhow sailing, fishing, snorkeling, diving, dolphin spotting and spa treatments. Several handmade cottages are dispersed in a wild garden along Wasini's coast line. They include: Wasini Restaurant, blue cottages, Mpunguti Lodge and Restaurant, Kituba's guest House, Mpunguti Campsite, Home stays with Fatuma, and Home stays with Abrisha. Special care has been taken to leave the environment as untouched as possible and the bush stretches right into the rocky compound situated beyond the outskirts of the main village. The study area was the preferred choice because it is an exotic island destination with various ecotourism projects for example Wasini Women Group and Shimoni caves. The island is comprised of people who are mainly the Digo tribe. It was one of the routes used by slave traders. The Kaya Kinondo is also linked with the island.

\section{Research Design}

This study adopted descriptive research design which basically aims at describing the state of affairs in a study area (Kombo \& Tromp, 2006). A research design is a procedure for collecting, analyzing, and reporting research in quantitative and qualitative research (Creswell, 2012).

\section{Target Population}

The target population for this study was the small island communities living adjacent to Wasini Island. The target population is approximately 3,000 people who live on the Island (Kenya National Bureau of Statistics, 2010).

\section{Sampling Procedures}

Sampling techniques. Two main sampling techniques were used, namely, purposive and systematic random sampling. Purposive sampling technique was used to recruit key respondents from the target population for the interviews and focus group discussions (FGD). The target respondents for interviews were those people who have the knowledge on ecotourism development in the study site and who were willing to provide a detailed account of the effect of the ecotourism projects on the socio-economic development of the local people. Purposive sampling was also used to select members of the FGD who were homogenous in nature in the sense that it comprised women only. This type of sampling technique is appropriate in this study because the population to be studied is somehow difficult to locate and some members are thought to be more appropriate (knowledgeable and experienced) for the study than others.

Purposive sampling technique employs the discretion of a researcher in picking of cases or it picks cases with a specific objective in mind (Kothari, 2004). This type of sampling technique is appropriate if the population to be studied is difficult to locate, or if some members are thought to be more appropriate (knowledgeable or experienced) for the study than others (Neumann, 2000).

Systematic random sampling was used to recruit respondents for surveys. Respondents were selected regardless of whether they are involved in tourism activities or not. This is because this technique was much easier to administer and saves time and money. According to this sampling technique, all members of the population under study have the same probability of being selected (Altinay \& Paraskevas, 2008). 
Using this procedure, each element in the population has a known and equal probability of selection. This makes systematic sampling functionally similar to simple random sampling. It is, however, much more efficient (if variance within systematic sample is more than variance of population). The researcher ensured that the chosen sampling interval does not hide a pattern. An entry point was also selected. Systematic sampling is to be applied only if the given population is logically homogeneous, because systematic sample units are uniformly distributed over the population.

Sample size determination. According to O. Mugenda and A. Mugenda (2003), the following method used in social science research was used to determine the sample size:

$$
n=\frac{z^{2} p q}{d^{2}}
$$

where:

$n=$ The desired sample size;

$z=$ The standard normal deviate at the required confidence level;

$p=$ The proportion in the target population estimated to have characteristics being measured;

$q=1-p$

$d=$ The level of statistical significance set.

O. Mugenda and A. Mugenda (2003) added that if there is no estimate available of the proportion in the target population assumed to have the characteristics of interest, as is the case in the current study, $50 \%$ was used. In this case, the proportion of the study's target population with the required characteristics is 0.50 , the $z$-statistic is 1.96 , and the desired accuracy is at the 0.05 level, then the sample size of this study is:

$$
n=\frac{(1.96)^{2}(0.50)(0.50)}{(0.05)^{2}}=384
$$

Generally, the research assistants were required to meet the following requirements aimed to ensure that they were sufficiently familiar with their respective communities. First, assistants should have lived on Wasini Island for at least five years; second, assistants should be conversant with the actual daily community life; and third, assistants should be involved actively in the local community's affairs, particularly, through organized groups such as women groups and youth groups. Moreover, the study targeted a population of 1,000 using questionnaires, where 320 respondents were reached out of a possible 384 as depicted in Table 1. In total, 20 interviewees were targeted, but only 15 responded, while all the eight FGD respondents responded to the study.

Table 1

Sample Size Distribution

\begin{tabular}{lcc}
\hline Research method & Target population & Sample size \\
\hline Questionnaire & 1,000 & 384 \\
Interviews & 20 & 15 \\
FGD & 8 & 8 \\
Total & 1,028 & 407 \\
\hline
\end{tabular}

\section{Data Collection}

Both primary and secondary sources of data were utilized. Primary data were obtained using semi-structured questionnaires, semi-structured interviews, and FGDs. Secondary data were gathered from 
published and unpublished sources such as journals and books. Questionnaires, interview, and FGDs questions covered items on the effect of ecotourism on various indicators on the quality of life. Structured interviews were used on private and public sector representatives where the former included managers of lodges and hotel on the island and the latter included government representatives from tourism sector. It also involved local community opinion leaders including intellectuals, non-governmental organization officials, religious leaders, local leaders, women and youth group leaders and politicians.

The questionnaires were administered to the general members of the local community at the eco-lodges, community meetings (barazas), shopping centres, and residential sites. In order to enhance the reliability of the questionnaires, a pilot study was undertaken to pre-test a sample of 30 of the questionnaires which is about $10 \%$ but according to De Vaus (2002) between $5 \%-10 \%$ is the recommended sample size for pretesting. They were edited and refined in the light of the results of the pilot study. Questionnaires were piloted to iron out any ambiguities and tested and purged using the Statistical Package for Social Sciences (SPSS) Cronbach Alpha technique for reliability. According to De Vaus (2002), a reliability of $0.70(70 \%)$ or higher will qualify the reliability of the research instruments. Similarly, questionnaires for the current study had a reliability coefficient alpha of 0.742 . In addition, they were invariably re-examined and technical defects were minutely scrutinized and removed.

\section{Data Collection Instruments}

Questionnaire surveys. The study utilized semi-structured questionnaires which contain both open and closed questions. A total of 384 questionnaires were administered by the researcher with the assistance of a research assistant. The questionnaires covered items on the effect of ecotourism on the various indicators of the quality-of-life. The questionnaires were administered to the general members of the local community members at the eco-lodges, barazas, shopping centres, and residential sites using simple random sampling technique. One of the best-known probability sampling techniques, this is, despite its name, neither simple nor random (in the sense of accidental or unsystematic). According to this sampling technique, all members of the population under study have the same chance (probability) of being selected (Altinay \& Paraskevas, 2008). As a result, every third person passing the strategic locations was selected for interview (De Vaus, 2002).

Key informant interview. The study also adopted a structured interview following an interview guide. Interview schedules covered items on the effect of ecotourism on the various indicators of the quality-of-life (De Vaus, 2002). All the respondents were administered with the same set of questions during the interviews. Interviews were administered by the researcher to 15 local community opinion leaders including religious leaders, local leaders, women groups' leaders, youth groups' leaders and politicians. Appointments were made with the key informants and places of their choice were used for the interviews. While interviewing, the researcher maintained a friendly and informal approach, whereby the researcher used friendly greetings and even made an attempt to know the cultural pattern and daily routine of the interviewees. In addition, all possible effort was made to establish proper rapport with the interviewee. More importantly, the interviewer listened with understanding, respect and curiosity during the interview session (Bryman, 2012).

FGD. The researcher used this data collection method to gather data about the effect of ecotourism initiatives on socio-economic development of small island communities living on Wasini Island. It is a method for collecting qualitative data through a group interview on a topic chosen by the researcher (Morgan, 2008). Questions were asked in an interactive group setting where participants were free to talk with other group 
members and the researcher was the moderator. The focus group was homogeneous in nature and comprised of eight members, all of whom were women. The women were selected for the FGD because it is the women group at Wasini that is conspicuous on matters of ecotourism, therefore the researcher deemed that this group was the most appropriate to be interviewed as a group. The group discussion was recorded using an audio recorder and took a maximum of 90 minutes. The FGD was administered by the researcher being assisted by a research assistant. Respondents for the FGD sessions were derived from the questionnaire survey respondents who showed a thorough understanding of issues for further probing.

\section{Data Analysis and Presentation Techniques}

Both quantitative and qualitative data analysis procedures were used as detailed in the ensuing sections.

Quantitative data analysis. The purpose of this section of data analysis was to determine the extent to which various sub-groups might differ in their evaluation towards ecotourism development. SPSS, Version 20.0 software was used for both descriptive analysis and inferential analysis (SPSS, 2010). Descriptive statistics was used to describe what is going on in the data and mainly take the form of frequencies and percentages. The 5-point Likert scale was coded as strongly agreed (1), agreed (2), neutral (3), disagreed (4), and strongly disagreed (5). Chi-square tests on contingency tables were used to test whether any significant differences exist among demographic variables and responses on ecotourism ventures' contribution to sustainable livelihood. The chi-square test for independence, also called Pearson's chi-square test or the chi-square test of association, is used to discover if there is a relationship between two categorical variables. Multiple regression was used to test multiple variables with significant differences (De Vaus, 2002). Analysis of variance (ANOVA) was used to analyse the variances where the dependent variable was ecotourism initiatives and the independent variables were the financial, physical, natural, human and social assets.

Qualitative data analysis. Since the data collected from the interviews were in form of open-ended verbal descriptions in field notes, transcriptions of audio recording and photographs; data analysis involved organizing, categorizing and identifying of key themes emerging from data collected. Interview questions and answers were examined and a set of categories were developed. The categories were examined for similarities and differences. Unique patterns within the data and between categories for each single organization were identified (Clark \& Creswell, 2015).

\section{Validity and Reliability of the Study}

This refers to the validity and reliability of questionnaires and interview schedule as data collection instruments. In order to enhance the reliability of the questionnaire, pilot study was undertaken for pre-testing it. Then, the questionnaire was edited in the light of the results of the pilot study. In addition, the questionnaire was invariably re-examined and technical defects were minutely scrutinized and removed.

\section{Results}

\section{Introduction}

This chapter presents the results of the study including the demographic information of the respondents, relationship between ecotourism and contribution of ecotourism initiatives to the assets of the communities, relationship between ecotourism initiatives and the entitlements of the communities and attitude of the local community towards ecotourism development. 


\section{Demographic Information of the Respondents}

Concerning gender, the male respondents were $60 \%$, while the females were $40 \%$ and this varied between the respondents $\left(\chi^{2}=13.762, \mathrm{df}=1, p=0.001\right.$; see Table 2$)$. The proportion of age of the respondents decreased with the age category. The age category of 18-30 years had the highest (67.2\%) followed by 31-40 years with $24.7 \%$. The age category of $41-50$ years had $6.9 \%$ while $51-60$ years and over 60 years had $0.9 \%$ and $0.3 \%$, respectively and this varied between the respondents $\left(\chi^{2}=76.238, \mathrm{df}=4, p=0.001\right)$. On marital status, the majority $(61.9 \%)$ were single, $32.5 \%$ were married while $3.4 \%$ were separated. Those who were divorced were $1.9 \%$ and widowed were only $0.3 \%$ and this varied significantly between the respondents $\left(\chi^{2}=74.371, \mathrm{df}=4, p=0.001\right)$. On the level of education, the majority $(55.9 \%)$ had primary education while secondary and tertiary had $36.6 \%$ and $5.9 \%$, respectively. University $(1.3 \%)$ and none $(0.3 \%)$ had the lowest education level and this differed significantly between the respondents $\left(\chi^{2}=60.590, \mathrm{df}=4, p=0.001\right)$.

Table 2

Gender, Age, Marital Status, and Highest Level of Education of the Respondents

\begin{tabular}{|c|c|c|c|c|}
\hline Variable & Frequency & Percentage $(\%)$ & Chi-square & $P$-value \\
\hline \multicolumn{5}{|l|}{ Gender } \\
\hline Male & 192 & 60.0 & \multirow{2}{*}{13.762} & \multirow{2}{*}{0.001} \\
\hline Female & 128 & 40.0 & & \\
\hline \multicolumn{5}{|c|}{ Age of respondents } \\
\hline $18-30$ years & 215 & 67.2 & \multirow{5}{*}{76.238} & \multirow{5}{*}{0.001} \\
\hline $31-40$ years & 79 & 24.7 & & \\
\hline $41-50$ years & 22 & 6.9 & & \\
\hline $51-60$ years & 3 & 0.9 & & \\
\hline Over 60 years & 1 & 0.3 & & \\
\hline \multicolumn{5}{|l|}{ Marital status } \\
\hline Single & 198 & 61.9 & \multirow{5}{*}{74.371} & \multirow{5}{*}{0.001} \\
\hline Married & 104 & 32.5 & & \\
\hline Separated & 11 & 3.4 & & \\
\hline Divorced & 6 & 1.9 & & \\
\hline Widowed & 1 & 0.3 & & \\
\hline \multicolumn{5}{|c|}{ Highest level of education } \\
\hline Primary & 179 & 55.9 & \multirow{5}{*}{60.590} & \multirow{5}{*}{0.001} \\
\hline Secondary & 117 & 36.6 & & \\
\hline Tertiary & 19 & 5.9 & & \\
\hline University & 4 & 1.3 & & \\
\hline None & 1 & 0.3 & & \\
\hline
\end{tabular}

Note. Source: Field data, 2013.

According to the religion of the respondents, the majority (84.7\%) were Muslims followed by Christians $(14.4 \%)$ while traditional and none were $0.6 \%$ and $0.3 \%$, respectively and this varied between respondents $\left(\chi^{2}=10.093, \mathrm{df}=3, p=0.018\right.$; see Figure 1). 


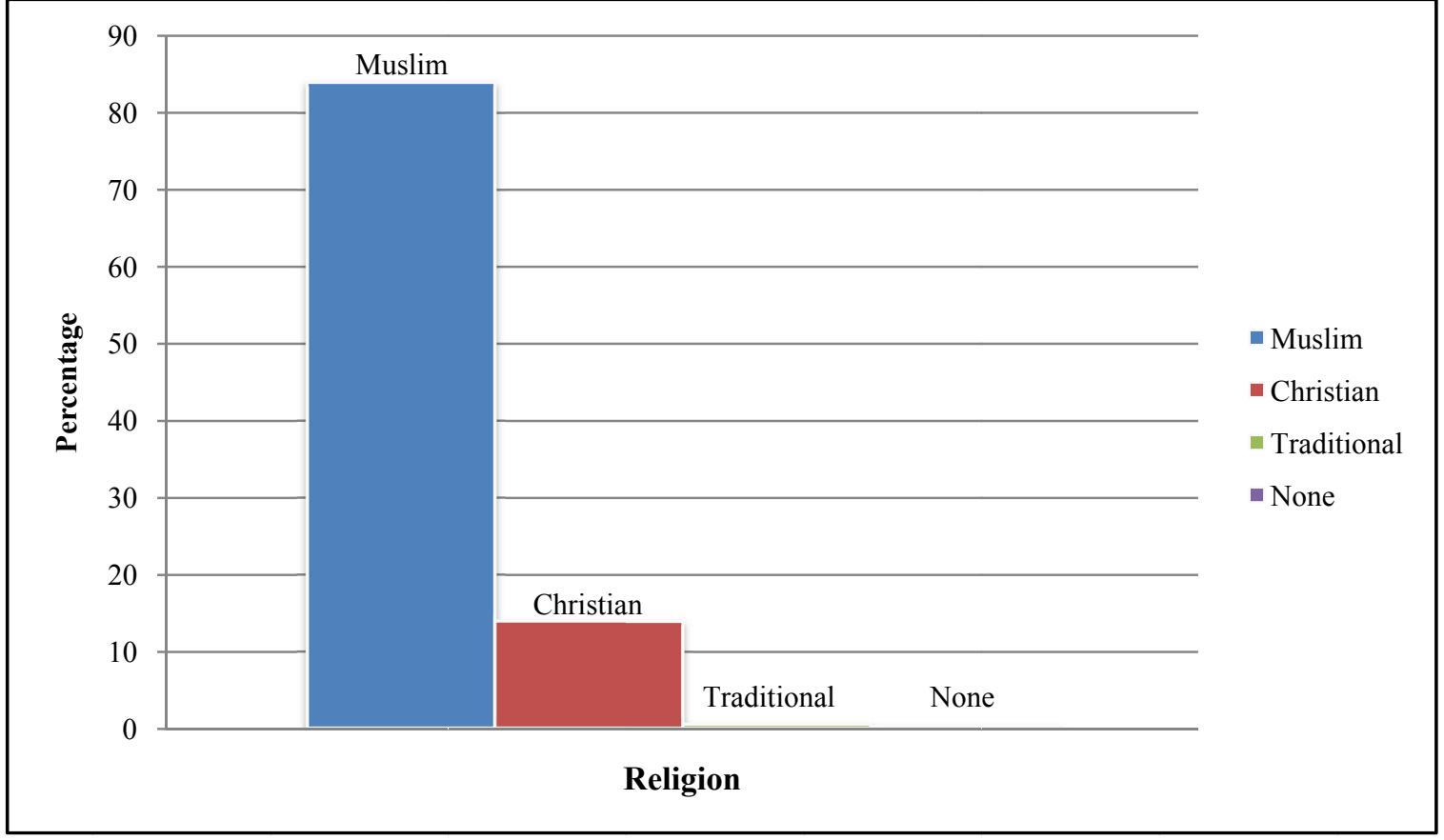

Figure 1. Religion of the respondents. Source: Field data, 2013.

The occupation of the respondents ranged from student (30\%), fishing (35.3\%), business person (18.1\%) and other occupational activities, namely, farming, homemaker and retired had $16.6 \%$ (see Figure 2) and this varied significantly between the respondents $\left(\chi^{2}=10.093, \mathrm{df}=5, p=0.018\right)$.

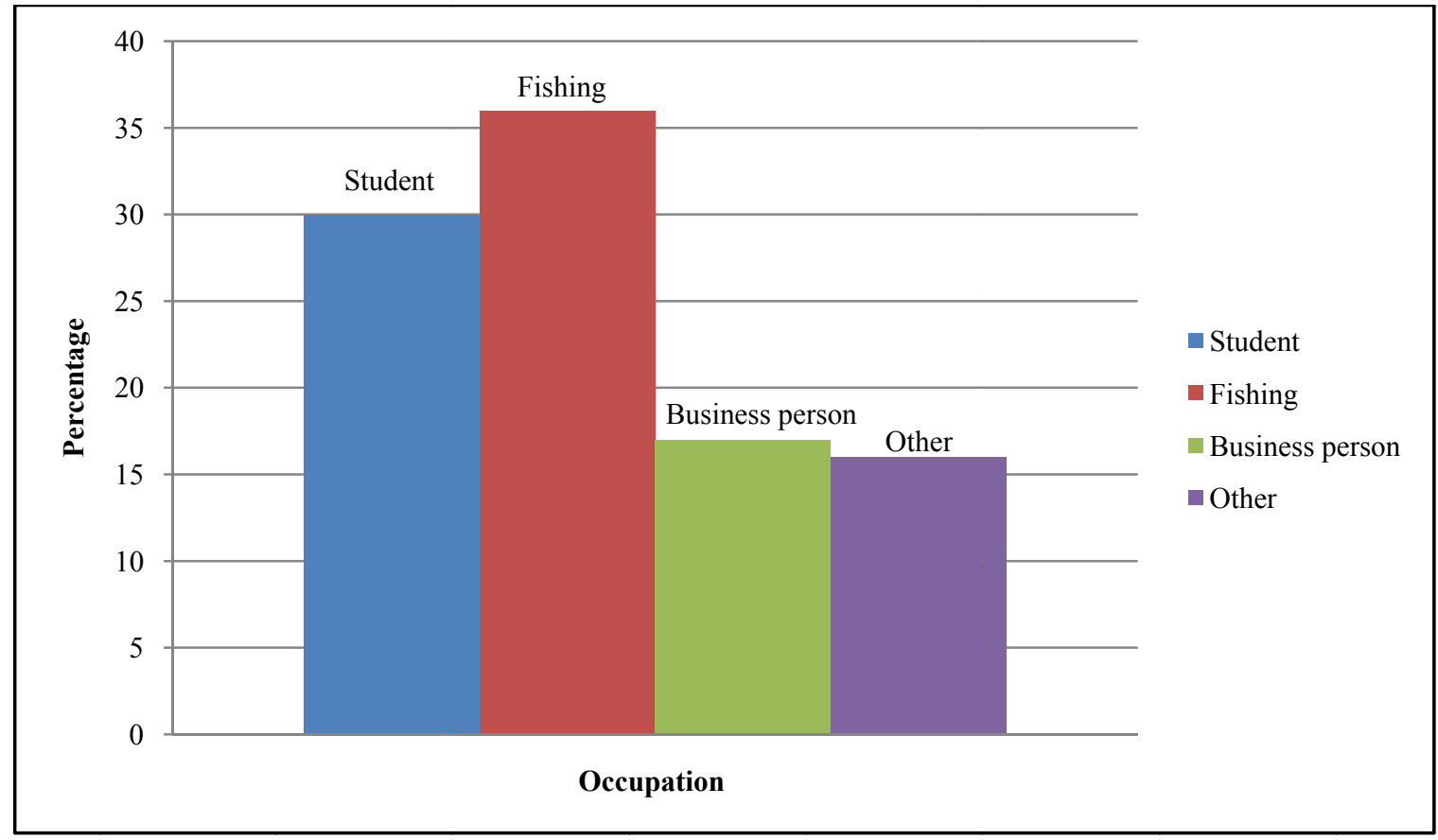

Figure 2. Occupation of the respondents. Source: Field data, 2013. 
On the level of income, the majority (43.8\%) of the respondents earned less than Kshs. 10,000 followed by Kshs. 20,001-Kshs. 30,000 with $26.6 \%$, while $12.5 \%$ earned between Kshs. 10,000-Kshs. 20,000. Those earning Kshs. 30,001-Kshs. 40,000 were 5.6\%, and the rest Kshs. 40,001-Kshs. 50,000 and above Kshs. 50,000 were $6.9 \%$ and $4.7 \%$, respectively and this varied between the respondents $\left(\chi^{2}=132.338, \mathrm{df}=5, p=0.001\right.$; see Figure 3).

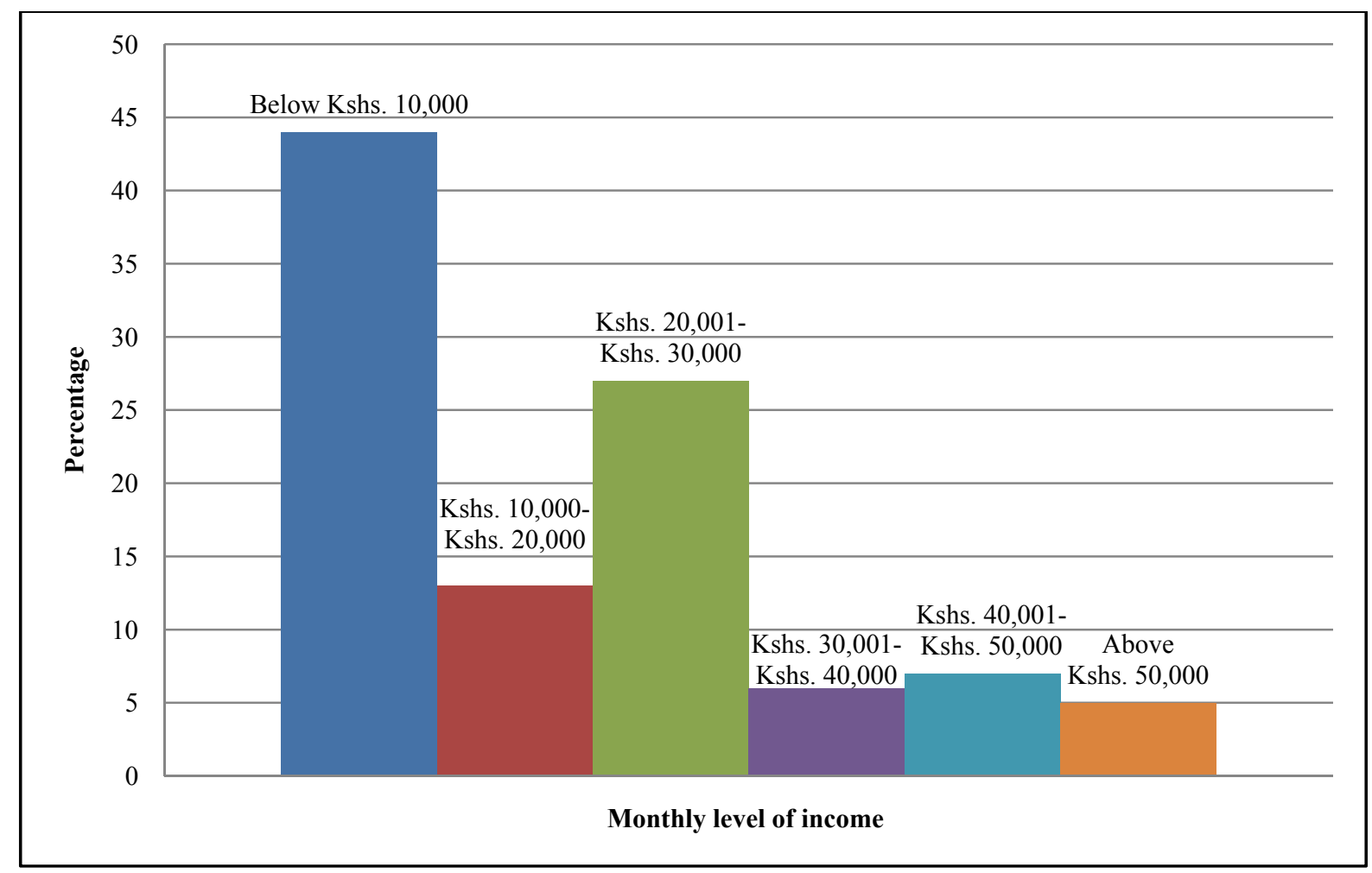

Figure 3. Monthly income level received by the respondents of Wasini Island. Source: Field data, 2013.

\section{Attitude of the Local Community Towards Ecotourism Development}

Determinants of attitudes of the local towards ecotourism. According to the respondents, the factors that determine the attitudes of the local community towards ecotourism included management $(50.3 \%)$, finances $(23.8 \%)$, education $(9.0 \%)$, participation $(2.2 \%)$, culture $(6.3 \%)$ and finally religion with $8.4 \%$ (see Table 3).

Table 3

Factors That Determine Attitudes of Locals

\begin{tabular}{lcc}
\hline Variable & Frequency & Percent $(\%)$ \\
\hline Management & 161 & 50.3 \\
Finances & 76 & 23.8 \\
Education & 29 & 9.0 \\
Participation & 7 & 2.2 \\
Culture & 20 & 6.3 \\
Religion & 27 & 8.4 \\
Total & 320 & 100.0 \\
\hline
\end{tabular}

Note. Source: Field data, 2013. 


\section{Attitude of the Local Community Towards Ecotourism Development}

Conceptual frameworks advanced to explain residents' perceptions and attitudes on ecotourism impacts include play, compensation, and conflict, attribution and dependency theories (Teye, Sirakaya, \& Sönmez, 2002). The social exchange theory, which has become more acceptable as appropriate for developing an understanding of these perceptions and attitudes, presents a framework to explain the relationship between individual benefits and perceptions of economic development (Perdue, Long, \& Allen, 1990). As applied to residents' attitudes, the social exchange theory stipulates that they seek benefits in exchange for something estimated as equal to the benefits they offer in return, such as resources provided to tourism developers, tour operators, and tourists. What residents offer additionally in this exchange includes their support for appropriate development, being hospitable, and tolerating inconveniences created by tourism such as pollution, traffic congestion and queuing for services (Teye et al., 2002).

Factors that have been shown to influence residents' perceptions and attitudes include the type and extent of host-guest interaction, importance of the industry to the community, extent of individuals' reliance on the industry, and the overall level of tourism development in the community (Murphy, 1985). Beyond these general factors, some specific ones include native-born status in the community, length of residency in the community (Liu \& Var, 1986), the extent of tourism concentration in the community (Haralambopoulos \& Pizam, 1996), economic reliance on the industry and distance of residence from the central tourism zone (Belisle \& Hoy, 1980). However, from the findings of the study, the factors that determine the attitudes of the local towards ecotourism were management, finances, education, participation, culture, and religion. Moreover, it realized that management was the main factor that determines the attitudes of the locals towards ecotourism on the Island. The study realized that there was a correlation between ecotourism initiatives and the entitlements of the communities.

\section{Conclusions}

In summary, ecotourism initiatives have the capacity to positively affect the livelihood of the local people. Moreover, ecotourism is a type of tourism that involves travelling to relatively undisturbed or uncontaminated natural areas with the specific object of studying, admiring, and enjoying the scenery and its wild plants and animals. Therefore, the aspect of sustainability comes out clearly when ecotourism initiatives are involved. The sustainability of touristic activities has a long-term effect on a destination. Wasini Island as a destination for ecotourism stands out to benefit if these initiatives are harnessed to benefit the local community. The manner in which the benefits of ecotourism initiatives are channeled especially towards the local community is of paramount importance.

In conclusion, the study findings show that ecotourism initiatives contribute significantly to the assets of the communities. Moreover, the attitude of the local community towards ecotourism development at Wasini Island was positive in the sense that most locals supported its initiatives. The attitudes of the community towards any form of tourism have an impact on its eventual development.

\section{Recommendations}

On the basis of the study findings, the researcher has the following recommendations: 
(1) Community participation in ecotourism: The stakeholders in the tourism industry should introduce more incentives to enhance the participation of local residents in tourism. This can be achieved through involvement in the management and conservation of ecotourism resources and attractions, and establishment of curio shops and hospitality facilities among others. Community participation has the impetus of ensuring that ecotourism activities are sustained both for this generation and posterity;

(2) Training: The locals should be adequately trained on matters pertaining to the matters of ecotourism. This training should be necessitated by all relevant stakeholders in the ecotourism industry in order to ensure that the locals are equipped with the relevant knowledge and skills to make use of the ecotourism resources in a sustainable manner;

(3) Governmental support: The government both national and county should support the ecotourism initiatives of the locals in terms of physical and financial aspects. Support from the county government is perhaps deemed more relevant and realistic because it is more in touch with the local residents compared to the national government. There should be effective and efficient structures which will ensure that the goals and objectives of the ecotourism projects get the relevant support from both the national and county governments.

\section{References}

Alderman, C. L. (2000). The economics and the role of privately owned lands used for nature tourism, education, and conservation. In M. Munasinghe, \& J. McNeely (Eds.), Protected area economics and policy: Linking conservation and sustainable development. Madrid: World Bank and IUCN.

Altinay, L., \& Paraskevas, A. (2008). Planning for research in hospitality and tourism. Amsterdam: Butterworth Heinemann.

Ashley, C. (2000). The impacts of tourism on rural livelihoods: Namibia's experience. Working Paper 128. London: Overseas Development Institute.

Ashley, C., \& Roe, D. (1999). Enhancing community development in wildlife tourism: Issues and challenges. IIED Wildlife and Development Series, No. 11. London: International Institute for Environment and Development.

Belisle, F. J., \& Hoy, D. R. (1980). The perceived impact of tourism by residents: A case study in Santa Marta, Colombia. Annals of Tourism Research, 7(1), 83-101.

Brandon, K. (1993). Basic steps towards encouraging local participation in nature tourism projects. In K. Lindberg, \& D. Hawkins (Eds.), Ecotourism: A guide for planners and managers. Bennington, VT: The Ecotourism Society.

Bryman, A. (2012). Social research methods (4th ed.). New York, NY: Oxford University Press, Inc..

Campbell, M. (1999). Ecotourism in rural developing communities. Annals of Tourism Research, 26(3), 534-553.

Cater, E. (1994). Ecotourism in the third world: Problems for sustainable development. Tourism Management, 14(2), 85-90.

Ceballos-Lascurain, H. (1993). Ecotourism as a worldwide phenomenon. In K. Lindberg, \& D. Hawkins (Eds.), Ecotourism: A guide for planners and managers (Vol. 1, pp. 12-14). North Bennington, Vermont: The Ecotourism Society.

Ceballos-Lascurain, H. (1996). Tourism, ecotourism, and protected areas: The state of nature-based tourism around the world and guidelines for its development. Gland, Switzerland: The World Conservation Union.

Chambers, R., \& Conway, G. (1991). Sustainable rural livelihoods: Practical concepts. Retrieved from http://www.smallstock.info/reference/IDS/dp296.pdf

Cheeseman, T. (2009). Conservation and the Maasai in Kenya: Trade-off or lost mutualism? Retrieved from http://www.environmentalism.net/

Christ, C. (1998). Taking ecotourism to the next level: A look at private sector involvement with local communities. In K. Lindberg, M. Eplerwood, \& D. Engeldrum (Eds.), Ecotourism: A guide for planners and managers (Vol. 2, pp. 183-195). North Bennington, Vermont: The Ecotourism Society.

Christie, I. T., \& Crompton, D. E. (2001). Tourism in Africa. Africa Region Working Paper Series No. 12. Washington, DC: World Bank.

Clark, V. L., \& Creswell, J. W. (2015). Understanding research: A consumer's guide (2nd ed.). London, UK: Pearson Education, Inc..

Cohen, E. (2003). The impact of tourism on the physical environment. Annals of Tourism Research, 5(6), 216-237. 
Collins, A. (1998). Tourism development and natural capital. Annals of Tourism Research, 26(1), 98-109.

Creswell, J. W. (2012). Educational research: Planning, conducting and evaluating quantitative and qualitative research (4th ed.). Boston: Pearson Education, Inc..

De Vaus, D. A. (2002). Surveys in social research (5th ed.). London: Routledge.

Diaz, D. (2001). The viability and sustainability of international tourism in developing countries. Geneva, Switzerland: World Trade Organization.

Eagles, P. F., Ballantine, J. L., \& Fennell, D. A. (1992). Marketing to the ecotourist: Case studies from Kenya and Costa Rica. Mimeo, Department of Recreation and Leisure Studies. Ontario, Canada: University of Waterloo.

Fillion, F. L., Foley, J. P., \& Jacquemot, A. J. (2005). The economics of global ecotourism. In M. Munasinghe, \& J. McNeely (Eds.), Protected area economics and policy: Linking conservation and sustainable development (pp. 235-252). Washington, DC: The World Bank.

Goeldner, C. (2001). Travel, tourism, and hospitality research: A handbook for managers and researchers. New York, NY: John Wiley \& Sons.

Goeldner, C., \& Ritchie, B. (2012). Tourism: Practices, principles, philosophies. New Jersey, NJ: John Wiley and Sons, Inc..

Goodwin, H. (1996). In pursuit of ecotourism. Biodiversity and Conservation, 5(3), 277-291.

Hamilton, M. (2003). The era of entitlement. Retrieved from http://writ.news.findlaw.com/hamilton/20030828.html

Haralambopoulos, N., \& Pizam, A. (1996). Perceived impacts of tourism: The case of Samos. Annals of Tourism Research, 23(3), 503-526.

Honey, M. (1999). Ecotourism in the shadow of Mt. Kilimanjaro: Lessons from Kenya and Tanzania. Contours, 9(1), 8-13.

Ikiara, M. M. (2001). Vision and long-term development strategy for Kenya's tourism industry. Nairobi: KIPPRA Discussion Paper No. 7.

International Recovery Platform. (2010). Guidance note on recovery: Livelihood. Kobe: International Recovery Platform Secretariat.

Kenya National Bureau of Statistics. (2010). National population and housing census. Nairobi: KNBS.

Kombo, D. L., \& Tromp, L. A. (2006). Proposal and thesis writing: An introduction. Nairobi: Pauline Publications.

Kothari, C. R. (2004). Research methodology: Methods and techniques (2nd ed.). New Delhi: New Age International Publishers.

Lindberg, K. (1991). Policies for maximizing nature tourism's ecological and economic benefits. Washington, DC: World Resources Institute.

Liu, J. C., \& Var, T. (1986). Resident attitudes toward tourism impacts in Hawaii. Annals of Tourism Research, 13(2), $193-214$.

Miller, A. (1997). Quantification of environment relevant activities of industries (tourism). Munich: German Institute for Tourism Research.

Mitchell, R. E., \& Reid, D. G. (2001). Community integration: Island tourism in Peru. Annals of Tourism Research, 28(1), 113-139.

Morgan, D. L. (2008). Focus groups. In L. M. Given (Ed.), The Sage Encyclopedia of qualitative research methods (pp. 352-354). London: Sage Publications, Inc..

Mugenda, O., \& Mugenda, A. (2003). Research methods: Quantitative and qualitative approaches. Nairobi: Acts Press.

Murphy, P. E. (1985). Tourism: A community approach. New York, NY: Plenum.

Nash, J. (2001). Eco-tourism: Encouraging conservation or adding to exploitation? Retrieved from http://www/Ecotourism_Encouraging_Conservation_or_Adding_to_Exploitation_1.htm

Neumann, L. (2000). Social research methods: Qualitative and quantitative approaches. Massachusetts: Needham Heights.

Ottichilo, W. K. (2000). Wildlife dynamics: An analysis of change in the Masai Mara ecosystem of Kenya (Doctoral thesis, The Wageningen University and Research Centre, Netherlands).

Page, S. (2009). Transport and tourism: Global perspectives. London: Pearson Education Limited.

Perdue, R., Long, P., \& Allen, L. (1990). Resident support for tourism development. Annals of Tourism Research, 17(4), $586-599$.

Randall, A. (1987). Resource economics (2nd ed.). New York, NY: John Wiley and Sons.

Ross, S., \& Wall, G. (1999). Evaluating ecotourism: The case of North Sulawesi, Indonesia. Tourism Management, 20(6), 673-682.

Scheyvens, R. (2002). Tourism for development: Empowering communities. Harlow: Prentice Hall.

Sindiga, I. (1996). Domestic tourism in Kenya. Annals of Tourism Research, 23(1), 19-31.

Sindiga, I. (1999). Tourism and Africa development: Change and challenge for tourism in Kenya. The Hague: Centre for African Studies. 
Slinger, V. (2000). Ecotourism in the last indigenous Caribbean community. Annals of Tourism Research, 27(2), 520-523.

Southgate, C. R. J. (2006). Ecotourism in Kenya: The vulnerability of communities. Journal of Ecotourism, 5(1-2), 80-96.

SPSS. (2010). Statistical Package for Social Science. Chicago, Illinois: SPSS, Inc..

Teye, V., Sirakaya, E., \& Sönmez, S. (2002). Resident's attitudes toward tourism development. Annals of Tourism Research, $29(3), 668-688$.

Tribe, J. (2006). The economic impacts of tourism. In J. Beech, \& S. Chadwick (Eds.), The business of tourism management. London: Pearson Education Limited.

United Nations Environmental Programme. (2001). Environmental impacts of tourism. Retrieved from $\mathrm{http}: / /$ www.unepie.org/pc/tourism/sust-tourism/environment.htm

Wall, G. (1997). Is ecotourism sustainable? Environmental Management, 21(4), 483-491.

Walpole, M., \& Goodwin, H. (2000). Local economic impacts of dragon tourism in Indonesia. Annals of Tourism Research, 27(3), 559-576.

Weaver, D. (1999). Magnitude of ecotourism in Costa Rica and Kenya. Annals of Tourism Research, 26(4), $792-816$.

Weaver, D. (Ed.). (2001). The encyclopedia of ecotourism. Wallingford, UK: CABI Publishing.

Wells, M. P. (1997). Is ecotourism sustainable? Environmental Management, 21(4), 483-491.

Western, D. (1993). Defining ecotourism. In K. Lindberg, \& D. Hawkins (Eds.), Ecotourism: A guide for planners and managers (pp. 7-11). North Bennington, VT: The Ecotourism Society.

Whelan, T. (1991). Ecotourism and its role in sustainable development. In T. Whelan (Ed.), Nature tourism: Managing for the environment (pp. 3-22). Washington, DC: Island Press.

Wight, P. (1993). Ecotourism: Ethics or eco-sell? Journal fo Travel Research, 31(3), 3-9.

Ziffer, K. (1989). Ecotourism: The uneasy alliance. Washington, DC: Conservational International. 